\title{
SAFFRON DREAMS-A JOURNEY OF EVOLVING IDENTITY
}

\section{Saima Majeed*Najia Asrar Zaidi** Dr. Zarina Waheed $* * *$}

\begin{abstract}
Saffron Dreams is a tale of a woman set in the immigrant milieu. It narrates how resolve and resistance can cope with hatred and weakness could harness indigenous strength against othering. The novel vividly portrays how distinct identities vanish, rebirth and evolve amidst the challenges; challenges that threaten lives and existence. It describes the epic struggle of a Pakistani woman, coming from a conservative society, whose dreams die. The research explores the evolving identity of the protagonist; the subject matter of identity is discussed with theoretical background. The Analysis revolves round Arissa who after sudden collapse of marital bliss is pushed to edges by society. The powerful longing for a renewed identity helps Arrisa prepare to live at the cost of sacrificing her 'hijab' whom she thinks as a symbol of bondage with her deceased husband. The beholder lives on with new version of her dreams marked by the desires to come out of the clutches of 'time' on canvass of her life colored with uncertainties and fatigued compromises. The study is exploratory in purpose, following the content-based mode of analysis.
\end{abstract}

Keywords: identity, other, self, tragedy, otherness Introduction

Tragic events stay permanently or at least quite long in human mind.

\footnotetext{
*, Research Scholar, National University of Modern Languages, Islamabad.

** Associate Professor, Department of English, University of Baluchistan Quetta.

*** Lecturer Department of Education Sardar Bahdur Khan Women University, Quetta.
} 
Tragedy of losing parents in tender age sticks to one's mind and shape behaviours in the impregnable age of that individual, but collective tragedies are devastating for societies, nations and mankind.

While earthquake, tsunamis, flood and famines are considered acts of nature and even infidels have to accept it. The migrations and wars are made of human erring, mischief or aggrandisement. The latest of manmade catastrophes is violence and terrorism and its worst manifestation in recent years is the 9/11 attacks in America. Like all major catastrophic happenings $9 / 11$ also provided background for creators of literature.

The Saffron Dreams, authored by Shaila Abdullah in the year 2009 is the reflection of America that strives to reveal the mysteries which shroud the history of Pakistani American Muslim women in America through a tale of trauma and healing in the aftermath of 9/11. The Novel can be touted as a piece of literature absurdist in its construction, operating in a superstructure and shrouded with chaos. As per Abdullah the growth of an individual is fostered by the rudimentary laws of the nature as well as pertinent passions that are illustrated through the nuances of the existence as well as the growth of the individual. It can be said that such growth process govern a stern presence pertaining to a cause as well as an effect relationship.

By putting forth the proposition of Sartre, "Existence precedes Essence", it is resolutely held by Sartre that existence is supplied with a hidden meaning put forth to visibility as well as success so far as men attempts to exercise their abilities in a full-fledged manner (Baggini p. 115-133).This theoretical proposition substantiates Abdullah's portrayal of Arissa. Within this captivating as well as the multifaceted novel, it has 
been put forth by the author that in order to gain a sense of stability, Arissa makes use of all her powers in totality, at the background of palpable and hovering losses. Abdullah is triggered with an outburst of an emotive dimension to Arrisa's personality, which is not the case before her spouse, Faizan died. She does not delve deeper into unearthing her psyche before the death of her spouse. According to Abdullah at that time Arissa's psychological state does not hold an immense significance. It is at this juncture of widowhood that the recesses of the mental constitution of the protagonist are worked upon by the author. Such development cannot be viewed as something simple; on the contrary it is laden with multifarious stages of complexity, which intrinsically influences the protagonist physical as well as psychological manner.

Arissa, a Pakistani American Muslim woman and her journey of evolving identity and self-discovery in the aftermath of 9/11 which takes her husband's life in an America that overnight changes the reactions of her existence and her hijab. To be precise, the reactions towards the Muslim community are changed after the 9/11 episode. The emotional trauma that Arissa goes through after 9/11 turns her into a stronger and independent woman. Arissa, being a Muslim becomes a representative of other socio-ethnic stereotypes in America. Abdullah brings forth the double marginality of a Pakistani Muslim American who is in continuous battle with herself and the society, in the aftermath of $9 / 11$.

In the face of social exclusion and othering, Arissa decides to let go of her 'hijab' (her identity) to make herself a part of the American society. Letting go of her 'hijab' indicates her willingness to forego her traditions for the sake of her unborn baby. In order to cope with a disabled child with multiple learning and health difficulties, Arissa lets go of her 
outward appearance of tradition and the marker of difference. But this act and the subsequent accomplishment of Arissa with regards to her life in America questions the multiculturalism of America. The multicultural America that is shattered after $9 / 11$ subtly pressurises and othering the outsider in Arissa to conform to the majority by letting go of her mark of difference, the hijab (veil).

Literature Review

The concept of self and the geopolitical foundation of the universebroke up after the collapse of the twin towers on September 11, 2001. Religious identity and ethnicity came under the microscope as people were marked "terrorists" on the basis of religious and racial integrations. Literature cannot remain immune to the changes, particularly; Pakistani fiction in English, since Pakistan's standing obtained ambiguity both as a foe and friend of the USA. This ambiguous status was moved to the average Pakistani particularly and South Asians generally out on the streets of any American city. While the world analyzed its opinion about South Asia, the South Asian literati also investigated their notions and concepts of identity in their fiction.

Identity is the trait; role, feature, social relationship, and social group membership that describe who the individual is.Identities could be aimed at the past as well as present. What was true of one and what is true of one. The person one wishes or expects to become and the person one feels obligated to or want to turn out to be or the person one fears one may turn into. Identities are orienting, they give a meaning-making lens and aim one's attention on little but not other features and characteristics of the sudden context. Self and identity theories consider that people care about themselves. They need to know who they are, and might use the self- 
knowledge and skills to make sense of the cosmos around them. Identity and Self are anticipated to impact what people are encouraged to think and to do, how they think and do. How they make sense of others and themselves, the actions they take, and the ability to control and the feelings to regulate themselves (Leary and Tangney p. 69-104).

According to Erick Erikson, people experience eight phases in life and each of the phase is characterised by psychosocial crisis (p.247). He further described that the crisis are related to the identity formation of the adolescents and late adolescents versus role confusion. Adolescents initially are confused about their roles in the society due to the transition of adolescents from childhood to the adulthood (Elkind p. 150-157). The role confusion let the adolescents to experience various roles, behaviours as well as activities. This experimentation contributed towards achieving a sense of identity for adolescents regarding their own personality and how they can efficiently play their roles in the society in which they have to live (McAdams and Zapata-Gietl p. 81-94). Cheng and Berman explains that successful resolution for identity crisis is very important for the psychological development of the individuals specially adolescents (Cheng and Berman p. 103-121). Meeus explained the concept of identity formation as described by Marcia who made use of two dichotomized concepts: commitment as well as exploration in order to measure the journey of young people through identity formation. She explained that exploration is promoted by the need to build nous of identity. On the other hand young people are actively engaged in pursuing different experiences with various different ideologies, role models as well as values. Commitment is related to the dedication, devotion and loyalty of the group towards achieving a certain goal, beliefs and values (Meeus p. 75-94). 
The immigration-based assimilation emphasized on adding the mainstream identity of a culture on the ethnic cultural identity of an individual and on the other hand, globalization- based acculturation emphasized on the specific integration of the local culture as well as global culture of an individual. The authors also explain that recognizing the cultural identities of an individual as incorporated is related to the psychosomatic modification. The process of cultural modification is a long term process whether through migration or through globalization. Smokowski and Bacallao examine the cultural assimilation acculturation gap which is found between parent and adolescents and also develop the behaviour hypothesis of the adolescents (Smokowski and Bacallao p. 661). The authors collected a socioeconomic random sample of total 481 Latino young people and found that, parent-adolescent conflict is one of the most widespread and strong risk factors for the aggression of adolescents (p. 670).

Identity is the basic of modern society and a focal point of socialpsychological research and theory. It is considered as the main hypothetical frameworks of specific identity creation (acculturation, social identity and developmental theories), major apparatuses of ethnic identity (a sense of belonging, social participation, ethnic self-identification and cultural practices and approach toward one's own ethnic group) and experiential researches on self-concept, self-esteem, ethnic identity relative to the majority culture, psychological adjustment, changes related to immigration generation, contextual factors and ethnic identity and gender(Omi and Winant p. 344).

The improvement of the identity centre design has been recorded in the volumes of this journal. It represents a developmental-social 
psychological idea to find data and formation which put together psychological and sociological perceptions of identity. Psychologically, it is based on the supposition that, met with global and local political and economic changes, late-modern institutional supports for creating firm improvement of changes have become more and more deficient, leaving several persons on their own mainly in terms of arranging their life courses in context of setting and reaching goals. Sociologically, it supposes the resources at individuals' disposal become crucial, specifically those social and emotional resources which can make easy the movement through, and intercession with, different social structures and improved contexts. In this logic, some inner and external resources are suggested to make it visible to mastery of external structures and functions(Cote and Schwartz p. 571-586).

The other is basically the individual who is not the same; basically, those who are socially and psychologically hegemonic impose the concepts of otherness and sameness. The otherness remains a multidimensional idea or concept dealt by Lacan in the philosophical anthropology, by Spivak in feminist discourse, and in "the Kantian notions of sense and taste(Buyze). In imperial discourse, the idea of otherness was added upon viz-a-viz the Us/Other binary which subsists between the colonized and colonizer. In Orientalism, Said handles the notion of the Orient as the other of the West: alien, inferior which can be conquered. Nevertheless, while this book encapsulates the "multiple identities", identity crisis and the Otherness of Islam, it also finds how Palmuk sketches the revival of the East and aims on the notion of Islam. The novel provides insight into the concepts of Otherness, due to the increasing hegemonic discourse forced upon the world by wounded but aggressive 
United States of America. Accepting the own otherness, theSouth Asian writer start academic debates and discussions by responding through their writings(about what it means to be a Muslim)(Buyze). Shaila Abdullah released her first novel Saffron Dreams in 2009, is a monumental depiction of the young Pakistan's widow in New York.It shows 9/11 tragedy from the perspective of a Muslim widows(Raja). She is coping with the alteration of her life and identity shaped by $9 / 11$. Sorrow, recollections, thoughts, and relationships dance sensuously in her journey of awareness alongside the rich flavours, whiffs, and colours of her conjugal reality. The novel portrays the spirit of the life of a Pakistani woman Arrisa, after the throes of 9/11. Arrisa's husband dies in the tower destruction. Shaila Abdullah knits a plot around racial tension and disturbing displacement, the depiction is so real which turned reader into the emotional distress. The influential and convincing tale of love and loss is weaved round fine dance between cultural variety and humanity. The author shows that losses can become strength and provide a sense of meaning and purpose. The birth of a disable child along with the devastating loss of spouse enables the reader to see the beauty in conception. This is a story of hopeful endings though not of happy one. Our lives are unsure, but with looking forward and bravery acrimony can be replaced by positive reception for what is present and in hand (Abdullah).

\section{Research Methodology}

The primary aim of the study is to look at identity depiction through the analysis of the novel Saffron Dreams. In order to support the analysis, literary close reading and textual analysis are pooled. To enhancethe analysis the insights from otherframeworks have also been 
drawn. This research incorporates psychological, sociological, political and literary discourse as conceptual tool. The research is narrative in nature contracting data from novel.

The research questions that this study undertakes are

1. How the post $9 / 11$ global scenario with its social and political dislocations shapes and fractures protagonist's identity formation?

2. What generalizations, preconceptions and the paranoia in the post $9 / 11$ world order led to the notion of the other and self in the novel?

Analysis/Discussion

"Father, Mother, and Me

Sister and Auntie say,

All the people like us are We,

And everyone else is They,

Rudyard Kipling (We and They)

Rudyard Kipling tends to address multitude of core psycho-social axioms through his poem "We and They" construed on the concept of otheror othering. While reading Saffron Dreams certain prudent questions come into mind. For instance, why an individual or a group of people belonging to a different religion particularly that of Islam is regarded as an "outsider" and "inferior" socially, politically and culturally with respect to the vast majority of the world? It can be argued in common parlance, a lay person who lacks any inimical broad "scientific" understanding of the society and polity of the aforementioned categories asks Aren't they all are the part of a common community of Homo sapiens (scientific terminology for human beings) Why politico-religious underpinnings only intensifies the "irrational" feeling of Islamophobia? 
A plethora of sociologists, psychologists as well as social anthropologists' in their maze of works have rendered the idea of identity construction, self and other in the quest of assessing as well as deducing from the landscape of contemporary issues. Among them, the theories of Erik Erikson, Edward Said, George Herbert Mead and Erving Goffman gauge the idea of othering and shape a vital and nuanced understanding of the notion of "social identity". At this juncture it would be rendered apt to undertake a rudimentary understanding of the sociological concept of othering, so the analysis of the novel can be appreciated in terms of the themes mentioned above. What then can be construed as othering, or prior to that the other, sociologically? The term other refers to the concept that was originally brought by a German philosopherGeorg Wilhelm Friedrich Hegel (1770-1831), also known as the father of German school of idealism. This concept of othersubsequently admired in recent times in Edward Said's seminal piece of literature, “Orientalism” (Brons p. 69-90).

Treating as other is a common occurrence; it is also a frequent discussion in conspiracy theory. For example, stating in terms of the contemporary global issues the birthers have perpetually tended to other Barack Obama (ex- President of United States America) by positing that he is not Real American as Kenya was his real place of birth turning his ascendancy to the presidency doubtful. Besides controversy on his birthplace, conspiracy theories also question his faith and religion. To prove their point, the brithers put emphasis on his middle nameHUSSAIN andignore "OBAMA which is an example of othering. The "birther-lite" variant publicized by Dinesh D'Souza asserts that Obama has a Kenyan, anti-colonialist philosophy.

(Kuryla p. 119-132). 
The social theorists believe that other is distinct from self. The early theories related to mind also focus on the concept of other and self. It is through the antecedent notion that there is in existence ofself and "other" that is extended to make "ourselves" and "those others," and thus the "us" and "them".Having grasped a basic sociological understanding of the concept of othering at this juncture, it would be prudent to understand Shaila Abdullah's Saffron Dreams in context of eotheringfollowed by the sociological elucidation of the idea of identity politics for the apt interpretation of the novel.

Saffron Dreams recounts the poignant, emotional and stimulating tale of Arissa Illahi and her literal as well as metaphorical journey etched with struggles. The struggle subsequently aims at fulfilling her distinctive yet juxtaposed roles as daughter, wife and mother respectively, in its ambit confronting the conflicting cultural expectations propagated by the opposing forces of the East and West and as well as the bourgeoning phenomenon of Islamophobia in the world's sole superpower(Shryock p. $260)$.

The man-engineered catastrophe of the 9/11 World Trade Centre Twin Tower attacks, led by the world's most notorious and also feared Islamic fundamentalist terrorist cult organization, blemished the nations and inhabitants at plethora of levels. The most obvious level being the morbid one, an overwhelming statistic of human beings belonging from several creeds, caste, race, religion lost their lives in a lightning matter of seconds.Secondly, at psychological level, concerning the minority sect of individuals belonging to the Muslim community, the sense of self as well as identity was severely ruptured and essentially dislocated. They Muslims 
were cast as the formidable others by the grieving and wounded majority of Americans (Sheridan p. 317-336).

Arissa Illahi, is one such other in a subtly as well as blatantly hostile land, a woman who lost her "Muslim" spouse in the catastrophic Twin Tower attack, and is heavily aggrieved like the significant nonMuslim Americans. However, her grief is not as adequate in tandem with the grief and anguish of her "fair" co-habitants. The following quote provide the construction of otherness, as explicated in Rabia Ashraf's reading of, The Saffron Dreams:

“As a young, expatriate, expecting widow, Arissa's first contact with conventional American society, after Faizaan's death is a heinous experience. Race conflict becomes explicit in the incident where she moves out of her apartment after bereavement period and is bullied and harassed by a clan of young American boys. Her veil is labelled as a façade and they blame her for being the perpetrator of Attack on Twin Towers. The conflict of race overlooks the basic similarities as members of same species. The consequential attitude of Americans hit by the Attack is hostility towards the 'yellow race'. There is a high degree of hatred nurtured by members of this society with those of other. Arissa thus becomes a victim of "Ethnocentrism". It is not written upon her forehead that she is a widow and an equal rather slightly more a victim of World Trade Centre Attacks but it does shine upon her forehead that she is a Muslim and a Pakistani experiencing a diasporic feeling, she is conscious of being 'suspended in mid-air' because of being homesick and a victim torn between two labels of identity, discrimination, racism and prejudice"(Ashraf p. 15). 
Arissa does not conform to the stereotypical notion of a Muslim woman; she is an independent, free-spirited Artist who until her spouse's death oscillates in ecstasy as a multicultural citizen and enjoys amalgam of values, ideas, and more widely the way of life. Prior to her husband's untimely demise during Twin tower attacks, her hijab (a traditional headgear which is worn by Muslim women, which covers most portions of their heads as well as shoulders) formed a constituent of her innate identity and pride, emblematic of her religious orientation. What then represents the idea of identity and the polity that is associated with the same? It is inimically significant to understand the idea of the sociological construction of identity in order to adequately appreciate the suitable interpretation of Shaila Abdullah's Saffron Dreams. George Herbert Mead's sociological exposition with respect to the notion of self and identity bourgeons with the assumption that there is in existence a reciprocal relationship between the self and society. The self is cardinal in effecting society by the actions of individuals institutions, networks, organizations and groups are created, correspondingly self is also affected by the society through its common ligua franca and the individual interact socially and thus take the role of other. Because Self is a the reflection of society so to understand self and its parts sociologically (identities) is indicative of the fact that an individual must inimically attempt to comprehend the society in which the self is in action, cognitively understand that the self is perpetually acting in a social context in which other selves exist(Mead p. 1-20).

In order to understand and appreciate in a better manner, the construction of one's identity and self in Saffron Dreams it is inimically important to gain a certain degree of rudimentary insight into the 
Gramsci's school of thought pertaining to hegemony. More preponderantly, post 9/11 phase, America more stringently turned into a hegemonic force, thereby eliminating the sedimentary scope for exclusive as well as indigenous identity that the minority have perpetually yearned for.ThePrison Notebooks by Gramsci's gives the unifying concept ofhegemony. Dr Femiawhile studying these patchy writings expounds the specific spirit of the concept expounds the specific spirit of theconcept. She looks into its theoretical stance and put froths the proposition that how Gramsci explain social stability(Colbert and Femia p. 230-232). In doing so a large number of Gramsci's neglected thoughts are highlighted and several widespread notions are knocked down. He emphasizes on economic factor,'contradictory consciousness' and relation between primary philosophical grounds and political philosophy.

The scholars have examined Gramsci's book critically and meet the answers of three hoary issues of Marxist theory. What could be the apt strategy for Marxist party operating within capitalist framework? Why the revolutionary mission is not carried out by western working class; and why the social states failed in their task of liberation?

The major quotient of Gramscian argument on hegemonic control is as follows,

The idea of a 'third face of power', or 'invisible power' has its roots partly, in Marxist thinking about the pervasive power of ideology, values and beliefs in reproducing class relations and concealing contradictions According to Marx the capitalism is reinforced by values and beliefs of ruling class and economic exploitation. He believes that false consciousnesses curtail the working class to assert and refuse their domination(Bates p. 351-366). 
Marx believes that false consciousnessis a theory of power. Lenin argued that the power of ruling class ideology inculcate trade union consciousness which urges to perk up material conditions within the capitalist system(Gill p. 243).

Gramsci takesMarx idea further along with his own idea of hegemony. He states that that capitalist state is made up of two overlapping spheres. The one is political run by force and the other is civil rule by consent.According to Gramsci civil society is a public field in which political parties and trade unions expand concessions from the bourgeois state.In this domain the beliefs are formulated hegemony is asserted in cultural life with the help of education institutions, religious institutions, media and other social institutions to create consent and authenticity.

The implications of Gramsci's politico social ideasare wide spread as he states that there are very limited chances of direct activist struggle to control the means of production.He believes that thisis only possible by fighting back through ideas to create a new hegemony.The abovementioned concept of counter-hegemonic fight back, as an alternate term also added to the idea that knowledge is a social construct that serves to legitimate social structures.

The Ongoing quest for self and identity in the post 9/11 phase is evident through following lines of Saffron Dreams "The wind tore the "veil" from my hand, making my task easier. I grasped the cold railing with one hand and swatted at the fleeting piece of my life with the other as the wind picked up speed. It teasingly brought the veil closer to my face. I could have grabbed it. Instead, I let it sail down toward the depths, its grave. I did not feel a sense of betrayal as I walked 
away from the pier, letting the wind dance with my hair for the first time. I pulled a few strands out of my eyes and looked back. The sun had just started to peek at the horizon, bleeding its crimson hue. It was a matter of perspective-to an onlooker I had removed my veil, but from where I stood, I had merely shifted it from my head to my heart. "Khuda Hafiz," I breathed. Who was I bidding farewell to? I wondered: the age-old tradition or the husband I had kept alive in my heart? "(Abdullah) p 4)

These lines are situated shortly after the traumatic experience of protagonist's spouse loss in the 9/11 Twin tower attack, followed by the relentless maltreatment and the discrimination meted out by the mainstream, American culture. The protagonist sheds a part of her identity (literally as well as metaphorically) which is tied to her existence as an archetypical Muslim woman and devout Muslim's wife. The disposal of her "cherished" hijab is a literal act of bereavement as well as is symbolic of beginning of a lifelong identity crisis. The self as well as the identity generated is associated in a symbiotic relationship with the society wherein one influences another. Through Abdullah's seminal piece of fictional exposition, it can be decreed that Arissa is an illustration of every singular case of the "tarnished" Muslim community whose sense of self as well identity development has been blemished beyond repair. Such a quest for identity as well as well a sense of self can be sought through Erving Goffman's dramaturgical approach towards the construction of self in his sociological piece, "The Presentation of Self in an Everyday Society". The major argument that has been propagated by sociologist in this magnum opus, wherein the process of interaction between the "actors" (according to Goffman, life is analogical to an endless stage theatrical performance, and the individuals are its actors) is heavily based on the societal 
construction of normative expectations of the others. In order to understand the ideas and beliefs of society through the manners of the individual Goffman's research is essential. The ideas, values and beliefs of a society can be understood through the behaviour of individuals. Goffman in addition take up a "dramaturgical approach" which concerns with the presentation of actor in the broader social context.Subsequently, it can be argued that Interaction in a society is considered as "performance" particularly defined by the social milieu. Goffman says that the roleattributed to the individual regardless of his/her deficient faithof the performance, the performance exists. Goffman gives the example of the physician give placebo to a patient in spite knowing its impotence, because patient demand it. Keeping in mind the above postulations the individual develops a relatable identity in need to interact with others. The procedure of creating identity on social realm come close to the concept of the "front," which is delineated in terms of "that part of the individual's performance which regularly functions in a general and fixed fashion to define the situation for those who observe the performance"(Goffman).Thus the front stage becomes the vehicle of consistency which enables others to understand the individual on the basis of anticipated character qualities with normative meanings." The front establishes proper "setting" "appearance" and "manner" as a "collective representation in accordance with the social role presumed by the individual/actor, joining interactive behaviour with the personal front. The actor thus is moved to accomplish the responsibility of the social role all the morein order to put forth a persuasive performance in the sphere of the front stage. Through these symbolic inter-actionist argument it can be contextualized that Arissa, the protagonist of the novel leads the social life torn between American 
demeanour to the critical "front stage" audience (the mainstream American Society), and craving the comfort as well as familiarity that essentially an expatriate does when confronted with a hostile and "multicultural" society.

"In all fairness, colours define me. Red reminds me of my marriage, the colour of the heady, fragrant mehndi or henna, intricately tattooed on my palms in the ways of tradition; the crimson shimmering wedding dress called sharara I wore the day I married Faizaan; yellow, the colour of ubtan, a paste I applied religiously to my face twenty days before my wedding in the hopes of getting the coveted bridal glow; and orange, the colour of saffron, dusty powder that with the right touch added flair to any dish. It was also the color that Faizaan dreamed of having on the cover of his unfinished book, a project he thought would make him a famous writer one day. But black reminds me of all that is sad and wrong in my life. Ironically, in this country, it validates my state of being a widow. It is also thecolor of my hijab - the dividing line between my life with Faizaan and theone without him. How different lives are from continent to continent.White, the bridal colour in the West, is the colour a widow is expected towear in the East, the colour the body is shrouded in before being buriedin the earth.The brush fell from my guilty hands, landing on the floor with a tired thud. I stepped back as if struck and looked at the picture in mad fixation. Staring back at me from the canvas, behind the dull last strokes that failed to hide the subject, were entwined towers engulfed in reddishblue smoke. And in the midst of the smouldering slivers was the face of aforlorn and lost child."(Abdullah) p.5-6)

Arissa is an artist, the identity crisis she faces in the wake of the catastrophic post $9 / 11$ epoch in the United States, is driven by her inability 
to retain the vestiges of her traditional identity in a foreign land (which is also not essentially foreign at the same time), yet being driven back to the odd and comforting vestiges of the homeland and the traditional marital life led by her with her husband.The myriad colours in these lines carry a fastidious symbolic connotation. Abdullah in an exponential manner deploys the colour black in order to put forth the depth of the loss and disintegration of one's identity and a multitude of pressing concerns related to it.

A Pakistani news paper Dawn reviews shaila Abdullah character Arrisa in an article titled "Above and Beyond" as "The female protagonists may be rich and educated or illiterate and impoverished but one thing they all share is the courage to overcome their hard ship. Like so many real Pakistani women they are not just victims but also fighters and perhaps more importantly, survivors" (Hussain, 2009).

Abdullah's protagonist, Arissais capable of upholding her relations and connections with life. The social conventions and ill-treatment could not victimize her because Abdullah portrays a fight- a continuous fight with a promise of survival and better future rather than end.

In order to understand the idea of otherness as well as the responses to it in a substantiated manner; it would be prudent to elucidate within the wider outline of Freudian theory the concept of a healthy personality from a genetic point of view. Personality development is an epigenetic progression which is correlated and depends upon the appropriate progress of each part at the appropriate time. The analysis of the growth process reveals these components of mental health developing in sequential stages: a sense of basic trust; a sense of autonomy; a sense of initiative; a sense of industry; a sense of ego identity; geniality; 
generativity; integrity.The aforementioned argument then can be deployed in conjunction with the gradually optimistic take by Abdullah on her female protagonist's responses to the fatally traumatic aftermath of the 9/11 catastrophe.

"My journey spans half a decade, from the biggest loss of my life to where I am now. It is a tale of grief and happiness, of control and losing control, of barriers and openings, of prejudices and acceptance, of holding on and letting go. It is about turning my heart inside out, mending it, and putting it right back in as it is about looking at life from the perspective of someone trapped in time. Finally, it's about filling shoes bigger than mine - and filling two with only one leg to stand on. This is the leg that over and over again will weaken with the weight it's expected to carry, falter, but eventually mend and march over the terrains of time"(Abdullah)p. 6).

These lines put forth the manner in which Abdullah constructs, deconstructs as well as re-construct the identity and self of her female protagonist, in the wake of otherness. In a plethora of manners, it can be stated that the event formed such a juncture with respect to the protagonists' life that it is akin to re-birth in terms of Arissa's personality development.

\section{Conclusion}

The past few decades have observed a noteworthy change in the angle of women in South Asian English fiction. A postcolonial woman fictional tradition is growing, changing, dynamic, and empowering women. Shaila Abdullah's novel Saffron Dreamsdiscovers the tragedy of 9/11 from the viewpoint of a Muslim widow (Roychoudhary et al. p. 3035). The study finds that female protagonist Arrisa slowly adapt to the 
new realities; this hints that though considered more vulnerable the women folks prove their capacity to adjust and adopt more than men. The novel revealed the common terrible insight in an extremely unusual method. Abdullah investigates an enduring need to outline nous by way of the random context of external conditions. The pictures of violence, annihilation, extinction and aloneness are reliably used by Abdullah to expose the empirical shade of the novel. By means of psychosomatic gradual expansion of the protagonist, she expresses how tussle exalts Arissa with a new and blessed life. Abdullah believes in the significance of a positive elucidation of the destitutions in existence. Converging upon emphasizing the way all through which Arrisa Illahi transfers from agonizing and negative opinion of life towards recognition and positivity is motivating, Abdullah draws out the concept that one can turn out to be a survivor from being a sufferer by using all emotional and mental abilities to tackle tough circumstances.

The novel draws an empirical part of fictions; it explains various types of travels wherein Arissa searches for her individuality and the reason, motive and importance of her life in in a world provoked with delusions and illogicality. Arissa literally fights for the need of her link with other individuals. As the story ends, Arissa gets a loyal description of her very own life. She is positive and self-assured about her life and future, her own behaviour draws her out of the indigent condition. The problemscountered by Arrisa after the death of her husband end in discoveries of the possibilities of life.

The reader comprehends that it is not the terrible attack, her disabled kid, or the incomplete novel of her husband which gave power to Arissa to meet the world and face all the challenges and difficulties. It is 
just about what bound each and every human being mutually even if they are from various countries, age and religions. All the way through the character of Arissa, Abdullah wishes to say the world that all people should not be judged on the basis of their religion. Abdullah shows that losses can become strength and provide a sense of meaning and purpose. This is a story of hopeful endings though not of happy one. Our lives are unsure, but with looking forward and bravery acrimony can be replaced by a positive reception for what is present and in hand. 


\section{REFERENCES}

Abdullah, S. Saffron Dreams: A Novel vol. 5, Loving Healing Press, 2009.

p.

Ashraf, R. "An Optimistic Evolution of Existence in Saffron Dreams by Shaila Abdullah." Language in India, vol. 15, no. 6, 2015, p. 15, http:www.languageinindia.com/june2015/rabiathesisfinal.pdf.

Baggini, J. "Jean-Paul Sartre: Existentialism and Humanism (1947)." Philosophy: Key Texts, 1 edition, Palgrave Macmillan, 1948, pp. 115-133.

http://www.palgrave.com/in/book/9780333964859?wt mc=ThirdP arty.SpringerLink.3.EPR653.About eBook.

Bates, T. R. "Gramsci and the Theory of Hegemony." Journal of the History of Ideas, vol. 36, no. 2, 1975, pp. 351-366, https://ondercetin.files.wordpress.com/2011/04/bates-1975.pdf.

Brons, L. L. "Othering, an Analysis." Transcience, a Journal of Global Studies, vol. 6, no. 1, 2015, pp. 69-90, https://philpapers.org/archive/BROOAA-4.pdf.

Buyze, D. M. Cultural Taste \& the Postcolonial Other. 2005. http:Slought.org, November 2013.

Cheng, M. and S. L. Berman. "Globalization and Identity Development: A Chinese Perspective." New directions for child and adolescent development, vol. 2012, no. 138, 2012, pp. 103-121, doi:10.1002/cad.20024.

Colbert, J. G. and J. V. Femia. "Gramsci's Political Thought: Hegemony, Consciousness, and the Revolutionary Process." vol. 33, no. 3, 1986, pp. 230-232, http://www.jstor.org/stable/20100173.

Cote, J. E. and S. J. Schwartz. "Comparing Psychological and Sociological Approaches to Identity: Identity Status, Identity Capital, and the 
Individualization Process." Journal of adolescence, vol. 25, no. 6, 2002, pp. 571-586.

Elkind, D. "Erik Eriksons Eight Ages of Man: One Man in His Time Plays Many Psychosocial Parts." New York Times magazine, 1970, pp. 150-157, https://www.pdx.edu/sites/www.pdx.edu.ceed/files/sscbt Eriksons EightAgesofMan.pdf.

Gill, S. Gramsci, Historical Materialism and International Relations. vol. 26, Cambridge University Press, 1993. p.

Goffman, E. "The Presentation of Self in Everyday Society." Garden City, 1959 , http://www.public.iastate.edu/ carlos/607/readings/goffman.pdf.

Kuryla, P. "Barack Obama and the American Island of the Colour Blind." Patterns of Prejudice, vol. 45, no. 1-2, 2011, pp. 119-132, http://www.tandfonline.com/doi/abs/10.1080/0031322X.2011.563 $\underline{150 .}$.

Leary, M. R. and J. P. Tangney. Handbook of Self and Identity. Guilford Press, 2012. p.

McAdams, D. P. and C. Zapata-Gietl. "Three Strands of Identity Development across the Human Life Course: Reading Erik Erikson in Full." The Oxford handbook of identity development, 2015, pp. 81-94.

Mead, G. H. "Mind, Self and Society." University of Chicago Press, 1934, pp. 1-20. The Classic Traditions, http://people.wku.edu/steve.groce/mindselfandsociety.p df. 
Meeus, W. "The Study of Adolescent Identity Formation 2000-2010: A Review of Longitudinal Research." Journal of research on adolescence, vol. 21, no. 1, 2011, pp. 75-94, doi:10.1111/j.15327795.2010.00716.x.

Omi, M. and H. Winant. Racial Formation in the United States. Routledge, 2014. p.

Raja, M. A. Constructing Pakistan: Foundational Texts and the Rise of Muslim National Identity 1857-1947. Oxford University Press, 2010. p.

Roychoudhary, M. et al. "Dismantling Patriarchy: Postcolonial Theme in the Short Stories of Namita Gokhale and Shaila Abdullah." vol. 4, no. 4, 2016, pp. 30-35, www.ijells.com.

Sheridan, L. P. "Islamophobia Pre and Postseptember 11, 2001." Journal of interpersonal violence, vol. 21, no. 3, 2006, pp. 317-336.

Shryock, A. Islamophobia/Islamophilia: Beyond the Politics of Enemy and Friend. Indiana University Press, 2010. p.

Smokowski, P. R. and M. L. Bacallao. "Acculturation and Aggression in Latino Adolescents: A Structural Model Focusing on Cultural Risk Factors and Assets." Journal of Abnormal Child Psychology, vol. 34, no. 5, 2006, p. 661. 